\title{
EL LÉXICO DEL ESPAÑOL DE LOS NEGOCIOS: PROPUESTA DE ANÁLISIS PARA SU ENSEÑANZA Y APRENDIZAJE
}

\author{
José Joaquín Martínez Egido \\ Universidad de Alicante. Grupo de investigación Griale ${ }^{1}$ \\ JJ.Martinez@ua.es
}

\begin{abstract}
Resumen
El español de los negocios se sitúa dentro de la lengua de especialidad del español económico. Por ello, en esta exposición se parte, en primer lugar, de la delimitación, tanto del concepto de lengua de especialidad en general, como del concepto de lengua de especialidad económica en particular, para, posteriormente observar cómo el español de los negocios se caracteriza por ser utilizado tanto por personas expertas como no expertas en diferentes contextos. Este uso comunicativo se realiza mediante un léxico dispar que incluye tanto expresiones técnicas, como semitécnicas y divulgativas. Para estudiar todo su conjunto léxico, en especial las unidades léxicas no técnicas, se propone un esquema que recoja toda su constitución léxica y, a partir de él, realizar diferentes actividades de enseñanzaaprendizaje para su aplicación en el aula.

PALABRAS CLAVE: léxico, español negocios, enseñanza.
\end{abstract}

\begin{abstract}
Business Spanish is part of the language for special purposes of Economics Spanish. Thus, we will start by defining both the general concept of language for special purposes and the particular notion of language for economics purposes. Then, we will remark that Business Spanish is used in different contexts by experts and non experts as well. This communicative use is made through a diverse lexicon, including technical, semi-technical and daily expressions. In order to study this whole area, specially nontechnical lexical units, we propose a diagram which covers all its lexical constitution, what ultimately will allow us to develop different learning and teaching activities for its implementation in the classroom.
\end{abstract}

KEY WORDS: lexicon, Business Spanish, teaching.

\section{Introducción: el concepto de lengua de especialidad}

El concepto de lengua de especialidad no deja de ser controvertido, ya que desde que despuntaron las primeras consideraciones sobre él, en la década de los setenta del pasado siglo ${ }^{2}$, no ha habido un consenso en cuanto a su definición. Se ha

1 Este artículo ha sido posible gracias al Proyecto de Investigación FFI2008-00179/FILO "Aplicaciones a la clase de español como lengua extranjera de la ironía y el humor", financiado por el Ministerio de Ciencia e Innovación y co-financiado con fondos FEDER (2008-2011).

2 Hoffman, L. (1976). 
utilizado diferenciándolo del concepto de lengua general, con diferentes grados de separación entre ambos, según los investigadores que se han ocupado de ellos ${ }^{3}$. Por este motivo, es fundamental partir de un concepto diáfano de qué es una lengua de especialidad, por lo que dedicamos esta primera parte de nuestro trabajo a describir y formular nuestra posición al respecto.

Partiendo de la consideración de la lengua general como diasistema en el que su configuración se realiza mediante la aglutinación de variedades, las lenguas de especialidad pueden ser caracterizadas como variantes o registros funcionales de comunicación, variantes diatécnicas, en un contexto profesional en el que sus usuarios suelen ser iguales y expertos (Martínez Egido, en prensa). Según nuestra definición, la ubicación del español de los negocios como lengua de especialidad dentro del código lingüístico quedaría explicitada en el siguiente esquema:

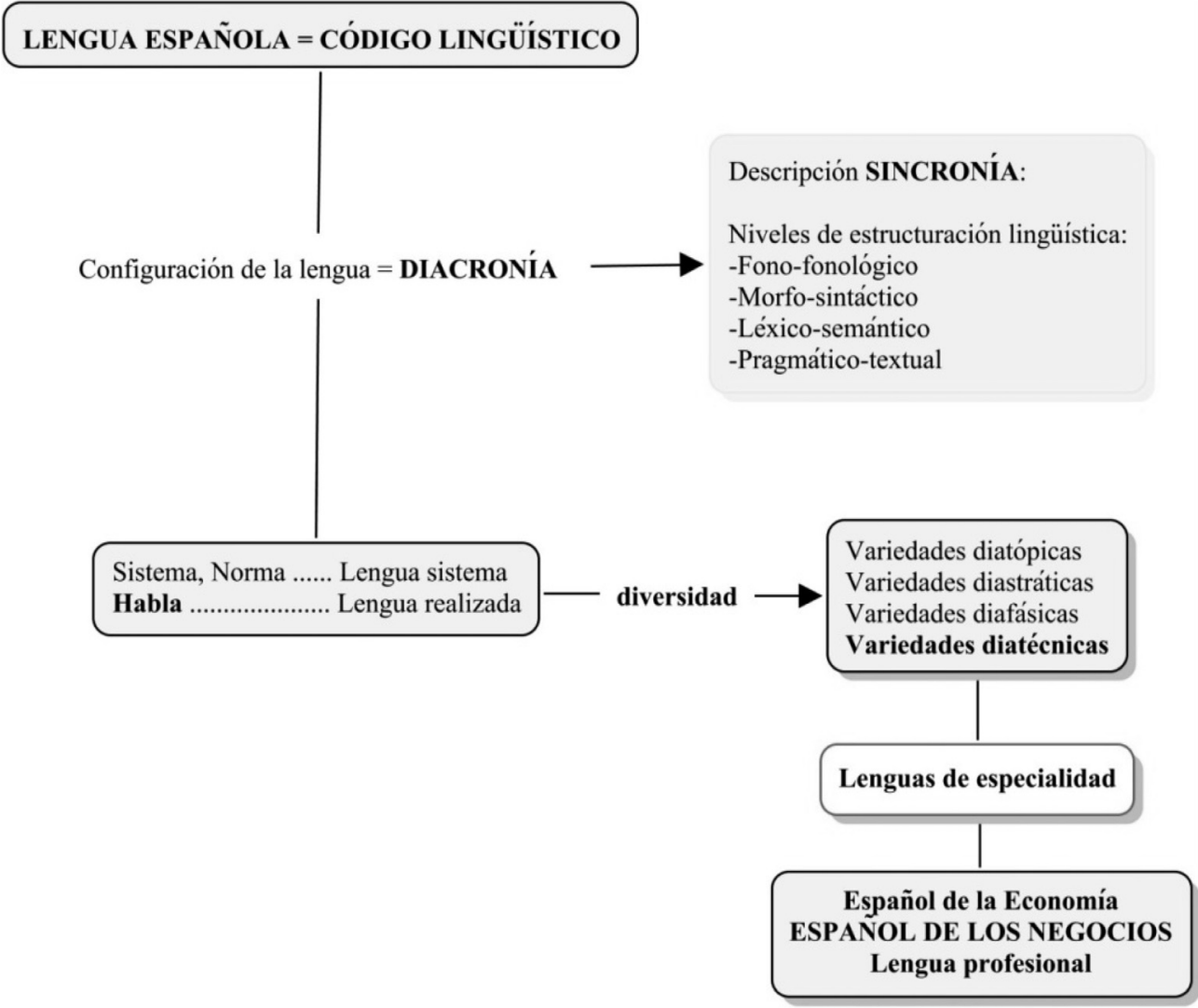

3 Entre los múltiples investigadores que han tratado esta cuestión destacan: Bungarten, T. (1990: 880-888); Rondeau, G. (1983); Sager, J. C. (ed.) (1993); Cabré, M. T. (1993); Hoffman, L. (1998); Cabré, M. T. (1999). Calvi, M.V y L. Chierichetti (eds.) (2006). En Felices Lago, A. (2005): "El español 
La lengua, como código, se configura diacrónicamente con un rendimiento sincrónico que los lingüistas han estructurado en cuatro niveles teóricos. Sobre la base de la estructura conceptual y formal está la lengua sistema (Saussure, 1945) que recoge todas las posibilidades de realización lingüística. Sobre ella actúa una norma lingüística (Coseriu, 1962), impuesta por el uso social en su devenir diacrónico, que se realiza en el habla, lengua realizada, en la que confluyen las peculiaridades diatópicas, diastráticas, diafásicas y diatécnicas de los hablantes. Y es precisamente en esta última variedad donde se ubican las lenguas de especialidad, las cuales participan de este constructo teórico comentado.

Por este motivo, el estudio de las lenguas de especialidad debe afrontarse desde una perspectiva funcional (Dick, 1997), en donde el enfoque primario debe ser el pragmático (Verschueren, 2002; Ruiz Gurillo, 2006) pues ellas sólo existen, y sólo tienen su razón de ser, como manifestaciones lingüísticas en determinados contextos de uso reducidos y específicos que exigen hablar de un tema concreto, es decir el campo o tema del discurso del que tratan (Eggins y Martin, 2000). A su vez, dependiente del tema tratado, debe haber por parte de sus usuarios unas intenciones definidas y condicionadas por la relación existente entre ellos (Moreno Fernández, 1998), el tenor, es decir, el grado de familiaridad o distancia que exista entre ellos determinará todo el proceso comunicativo, desde la selección del vocabulario, hasta la configuración de la macroestructura textual. De esta forma, a los participantes de una lengua de especialidad se les exigirá una madurez lingüística alta pues, ante todo, la utilización de este tipo de lengua debe asegurar, como primer propósito, una comunicación eficaz.

\subsection{El español de los negocios}

En lo referente a la lengua del mundo económico, siguiendo tanto la definición general de lengua de especialidad como el marco pragmático adjudicado para su estudio, nos encontramos con una amplia diversidad de posibilidades textuales (Alcaraz, 2000; Mateo, 2007), que irían desde el lenguaje divulgativo desarrollado entre no expertos o de experto a no experto, hasta el lenguaje técnico, de experto a experto, tal y como intenta reflejar el siguiente esquema:

con fines específicos y su desarrollo en España durante la última década", IDEAS (FH-Heilbronn), n ${ }^{\circ}$ 1, marzo, se realiza una síntesis de esta cuestión. http://www.ideas-heilbronn.org/archivo/1/elements/ artic/FelicesLago-El-desarollo.pdf (01-06-09). 


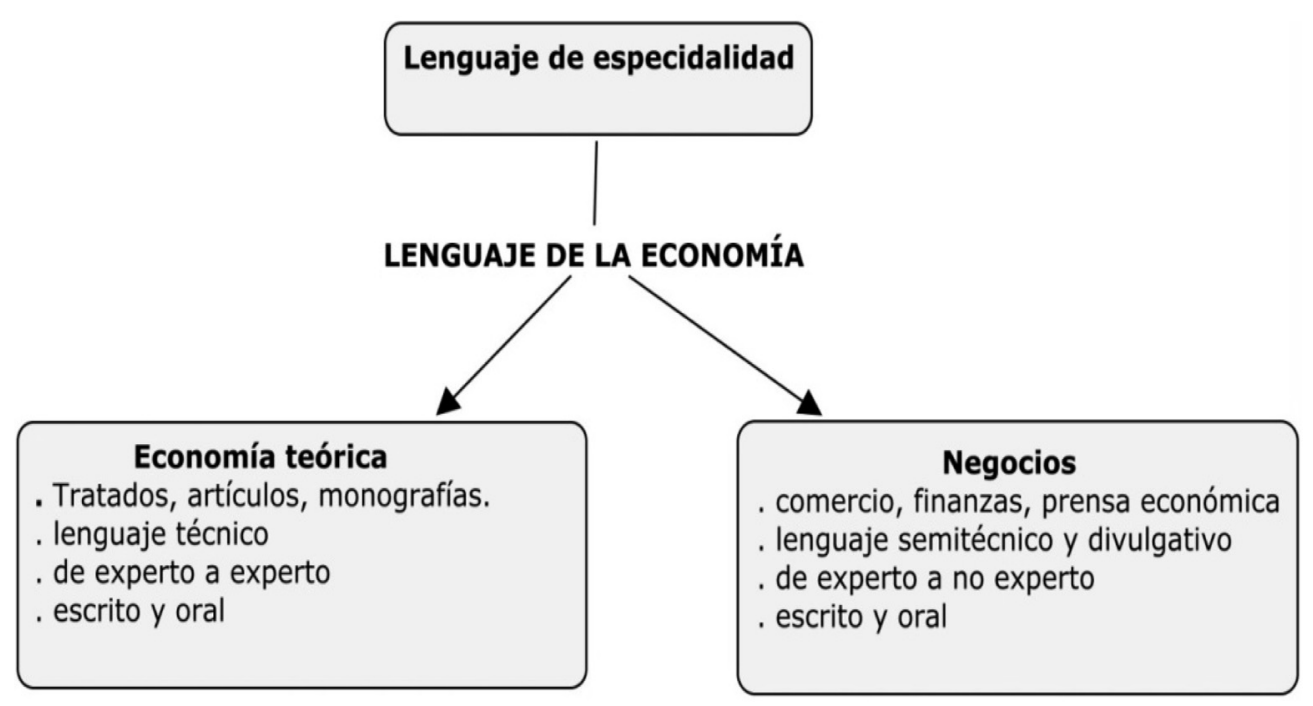

De esta forma, se puede hablar de un lenguaje de la economía general que se subdivide en dos grandes grupos caracterizados, en primer lugar, por el tipo de lenguaje, técnico o semitécnico y divulgativo que emplean. El tipo de lenguaje utilizado deriva directamente de la capacidad lingüística y conceptual que poseen sus usuarios, expertos o no expertos, dando lugar así a una amplia y diversa tipología textual que situaría en un extremo a los textos de la prensa económica, y en el otro extremo, a los textos de economía teórica. Entre ambos puntos, se emplazarían el resto de producciones textuales económicas, como serían las de negocios, las de comercio y las de finanzas (Martínez Egido, 2006; Martínez Egido, 2008a), teniéndose en cuenta también, que la producción de todos estos textos puede ser tanto oral como escrita. Por tanto, al hablar del español de los negocios nos referiremos a la lengua de especialidad económica caracterizada por un lenguaje que mezcla lo técnico y lo divulgativo, que no siempre se utiliza entre expertos y que tiene como finalidad la comunicación sobre temas económicos entre los ciudadanos.

Partiendo de esta idea, esta exposición trata de caracterizar este tipo de léxico y de proponer actividades de enseñanza-aprendizaje para su desarrollo pedagógico en el aula, tanto para un aprendiente español, como para uno que estudie nuestra lengua como LE.

\section{El léxico del español de los negocios. La prensa económica}

Los asuntos económicos han dejado de estar relegados a un ámbito concreto y parcial y se han extendido a una población mayoritaria, debido a la globalización 
que vivimos y al estar dentro de una sociedad marcada por el conocimiento y la información. Por ello, el conocer los temas económicos se ha convertido en una necesidad social demandada por un grupo social muy numeroso, por lo que es importante el que seamos competentes en la lengua de especialidad económica. Aunque es importante delimitar que dicha competencia no es necesaria en el ámbito económico técnico sino en el campo más cotidiano y divulgativo.

Dentro de éste último, como material referencial para nuestro propósito, destaca el que encarnan los textos de prensa económica, tanto por la actualidad temática que presentan, como por el proceso comunicativo en el que están insertos. Dentro de la casuística que éstos representan, se distinguen básicamente dos géneros periodísticos definidos por su finalidad, la cual condiciona también tanto su estructura como su redacción; a saber, la noticia, consistente en la transmisión de una información veraz y objetiva, cuya función comunicativa es la referencial, y el artículo de opinión, con el que se quiere convencer al receptor de una idea concreta, según la ideología del emisor, y en el que predomina básicamente una función comunicativa apelativa. En ambos tipos textuales, la clase de léxico que utilizan se convierte en uno de los elementos definitorios y caracterizadores.

Por todo ello, y en aras del objetivo de este trabajo, nos centraremos en el léxico de las noticias periodísticas económicas al considerarse, a priori, más denotativo y generalista que el léxico utilizado por un comentarista de opinión en sus columnas, ya que en este último caso, existe una mayor libertad personal para ejercer el periodismo.

\subsection{Procedimiento de análisis}

Para el análisis del léxico de la prensa económica (Martínez Egido, en prensa), hemos confeccionado una base de datos que recoge diferentes artículos periodísticos de cinco publicaciones diarias generalistas (El país, El mundo, ABC, La razón y Público) en sus secciones de economía, y de tres periódicos especializados en economía (Expansión, La gaceta de los negocios y El economista) desde noviembre de 2008 hasta ahora. De ellos se ha seleccionado y clasificado el léxico que han ido utilizando los periodistas en la redacción de sus noticias.

Con cada una de las unidades léxicas seleccionadas se ha confeccionado una ficha lexicográfica para poder delimitar su significado especializado. Para conseguir este objetivo se ha recurrido a tres diccionarios con planteamientos y finalidades diferentes, para así contar con una descripción léxica suficientemente amplia de cada una de las unidades léxicas recogidas; éstos han sido:

- DRAE en línea (www.rae.es). Con él se ha obtenido, en primer lugar, los diferentes significados y acepciones reconocidos como normativos en español. 
- Joan Corominas, Diccionario crítico etimológico castellano e hispánico 4 . En todos los casos, salvo en las unidades léxicas precedentes del inglés reciente, con él se ha constatado la etimología de las unidades léxicas seleccionadas para conocer cómo y desde cuándo están presentes en el devenir del español.

- Ramón Tamames y Santiago Gallego, Diccionario de Economía ${ }^{5}$. Conocidos los datos anteriores, con este diccionario se ha podido comprobar cuáles de las unidades léxicas son recogidas en él como términos económicos y constatar en qué coinciden o divergen en sus significados y acepciones con los recogidos en los dos diccionarios anteriores.

Un ejemplo de las fichas lexicográficas realizadas sería:

Corominas:

\section{Bolsa}

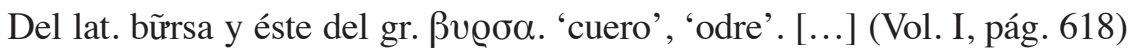

DRAE

(Del lat. bursa).

1. f. Especie de talega o saco de tela u otro material, que sirve para llevar o guardar algo.

2. f. Saco pequeño de cuero en que se echa dinero, y que se ata o cierra.

3. f. Recipiente de material resistente para guardar, en viajes o traslados, ropa u otras cosas, y que se puede llevar a mano o colgado del hombro. (Del nombre de la familia Van der Bourse, en Brujas).

1. Institución económica donde se efectúan transacciones públicas de compra y venta de valores, y otras operaciones análogas.

2. f. Lugar donde se efectúan estas transacciones.

3. f. Conjunto de operaciones con efectos públicos.

\section{Tamames}

Bolsa de Valores: Institución económica en la que se produce la contratación público-mercantil de toda clase de títulos valores: acciones, obligaciones, fondos públicos, etc. [...] (pág.)

\subsection{Resultados del análisis sobre el léxico económico}

Con la información que nos han proporcionado estas fichas lexicográficas y la observación de las unidades léxicas en los textos periodísticos en los que han sido

4 (1980), Madrid, Gredos.

$5\left(2000^{11}\right)$ Madrid, Alianza Editorial. 
utilizadas se ha establecido el siguiente esquema que recoge la constitución del léxico ${ }^{6}$ económico utilizado en la prensa actual española ${ }^{7}$ :

- Léxico originario del español.

Existen unidades léxicas que forman parte del acervo léxico del español desde los orígenes de la lengua y que poseen un significado léxico especializado en el mundo de la economía. Estas unidades léxicas se caracterizan por haberse estandarizado en la lengua común, aunque conservan alguna acepción que las hacen pertenecer a la lengua de especialidad económica. Ejemplos de estas unidades léxicas serían: Dinero, Economía, Mercado, Negocio y Comercio.

- Léxico no originario del español.

A) Léxico creado por el español mediante los procedimientos gramaticales y semánticos que su sistema le permite:

1) Incidencia en el significante: desinflación, OPEP, ciberagricultores, etc.

2) Incidencia en el significado:

a) Metaforización: Los zumos se pelean en la publicidad; Teléfonica esprinta en Europa.

b) Desautomatización: Con el pez detrás de la oreja.

B) Léxico procedente de otras lenguas. Préstamos lingüísticos:

1) De lenguas clásicas: Déficit, Superávit.

2) De lenguas modernas: Empresa, Finanzas, Bolsa.

De esta forma, cualquier unidad léxica recogida por la prensa económica española puede catalogarse como término económico mediante su estudio lexicográfico y clasificarse según los parámetros del esquema anterior.

6 Para conocer la constitución del léxico del español general, véase Martínez Egido, J. J. (2007a) y (2007b).

7 En este trabajo solamente se ofrece un pequeño esquema del estudio realizado sobre la constitución del léxico económico en la prensa española. Para una completa visión de este tipo de léxico y para conocer todo el proceso de análisis llevado a cabo, véase Martínez Egido, J. J. (en prensa), “Constitución del léxico utilizado en la prensa económica española actual”, Español Actual. 


\section{Enseñanza del léxico de los negocios. Propuesta de actividades}

Aplicado el procedimiento descrito anteriormente, la enseñanza del léxico de los negocios no se realiza de forma aislada sino que se inserta en el marco general que proporcione el curso de El español de los negocios que se programe. En nuestro caso, la enseñanza-aprendizaje del léxico está proyectada en el curso $^{8}$ que hemos diseñado y que hemos desarrollado dentro del Máster oficial en inglés y en español para fines específicos y empresariales en la Universidad de Alicante.

Este curso de El español de los negocios se divide en un tema de introducción a la lengua de especialidad de la economía y en tres bloques diferenciados que abarcan cada uno de ellos el estudio de una de las tres propiedades textuales necesarias, es decir, la coherencia, la cohesión y la adecuación, respectivamente. Aunque en cada uno de ellos se incluya el estudio y el análisis del nivel léxico de la lengua desde diferentes perspectivas y con distintas herramientas, es en el bloque II, relativo a la cohesión, donde se analiza pormenorizadamente el aspecto léxico al tratar como punto diferenciado la descripción de la terminología utilizada en el español de los negocios, tal y como recoge el siguiente índice de contenidos del bloque II:

1. El español de las finanzas. Caracterización general.

2. La cohesión como propiedad textual en el español de los negocios.

3. Elementos de cohesión textual:

a. Mecanismos de recurrencia:

a. Repeticiones de palabras que pertenecen a un mismo campo semántico.

b. Uso de sinónimos.

c. Uso de antónimos.

d. Empleo de palabras que comparten un mismo significado connotativo.

e. Uso de palabras que pertenecen a una misma familia léxica.

f. Palabras que pertenecen a un mismo registro idiomático.

g. Presencia de enunciados que tienen una estructura sintáctica semejante.

b. Mecanismos de sustitución:

a. Sustitución de una palabra por otra (sinónimos, hipónimos, hiperónimos).

b. Empleo de pronombres y determinantes anafóricos.

1. Empleo de deícticos.

2. La elipsis.

3. Empleo de adverbios.

c. Marcadores textuales:

a. Para estructurar el texto

b. Para estructurar las ideas (conectores)

8 Martínez Egido, J. J. (2008a). 

d. El párrafo (coherencia)
e. El registro (adecuación)

4. Rasgos morfosintácticos del español de los negocios

5. La Terminología:
a) Definición de término
b) Tipos de términos
c) Términos y unidades léxicas en el español de los negocios ${ }^{9}$

6. Tipología textual del español de las finanzas: la presentación oral

7. Técnicas comunicativas en el español de las finanzas.

La terminología es un rasgo definitorio de los textos de especialidad, aunque, como se ha constado en el estudio del léxico de los negocios realizado, en este ámbito el concepto de término debe entenderse como una unidad léxica con un significado concreto dentro de un discurso de especialidad, independientemente de que posea o no un significado diferente en la lengua general.

El alumno no suele tener problemas con la identificación y con el análisis de los términos que no funcionan como unidades léxicas en la lengua general. Pero, por el contrario, sí que suele encontrar dificultades con aquellos que sí lo hacen. Por este motivo, además de enseñar toda la teoría terminológica y de realizar las actividades pertinentes para que el alumno adquiera la competencia suficiente en esta cuestión, se realizan actividades diferenciadas para que observe el valor de otras unidades léxicas y expresiones que son utilizadas también en este tipo de discurso especializado. Esta cuestión todavía es más importante cuando el alumno no tiene el español como lengua materna.

\subsection{Actividades de clase con el léxico del español de los negocios}

Como ejemplos de la enseñanza y el aprendizaje del léxico utilizado en este tipo textual del español de los negocios, se presentan a continuación dos actividades concretas llevadas a cabo en las clases del español de los negocios en el máster ya reseñado.

\subsubsection{Actividad 1: recursos léxicos usados en la prensa económica}

Un ejemplo de actividad que recoge el léxico de los negocios que no puede ser estudiado con la teoría terminológica sería la que llevamos a cabo mediante 50 ti-

9 http://rua.ua.es/dspace/bitstream/10045/7495/40/17.PP\%2cbloque2\%2ctemas5\%2c6\%2c7\%2c8\% 2ccohesi\%c3\%b3n.pdf (20/04/2009). 
tulares y sus correspondientes entradillas del periódico El país, recogidos de mayo a agosto de 2007. Ejemplos de ellos son ${ }^{10}$ :

\section{- Telefónica esprinta en Europa}

La multinacional española se convierte en referente de las telecomunicaciones europeas batiendo a sus rivales por rentabilidad, clientes y capitalización bursátil. (pág. 1; 20-05-07)

\section{- Telefónica marca el paso en Europa}

La operadora española bate a sus rivales y se convierte en motor de las telecomunicaciones europeas. (pág. 5, 20-05-07)

La actividad se estructura de la siguiente forma:

1) Se entregan los titulares sin las entradillas a los alumnos. Ellos deben dar una interpretación de cada uno y expresar su sentido literal y buscar su posible sentido figurado.

2) Se realiza una puesta en común, primero en pequeños grupos (3 ó 4 alumnos) y luego en el conjunto de la clase (esta distribución siempre depende del número de alumnos existente).

3) Se entregan a los alumnos los titulares con sus correspondientes entradillas para que comparen las explicaciones dadas por cada uno de ellos con la realidad reflejada por el periodista.

4) Se realiza una valoración general sobre los recursos lingüísticos utilizados por los periodistas.

5) Se establece una clasificación de los recursos encontrados por parte del profesor para así obtener una visión clara de todos los recursos utilizados por los periodistas especializados en la redacción de las noticias económicas.

Con esta actividad se logra que los alumnos de español de los negocios conozcan este tipo de léxico característico de la lengua utilizada en los medios de comunicación económicos en España, el cual irá parejo al estudio de la terminología propia de esta lengua de especialidad ${ }^{11}$, mediante una metodología activa, pues serán ellos mismos quienes vayan descubriendo la forma de uso de la lengua económica.

10 El total de los 50 titulares se ofrece al final de este trabajo en el anexo 1.

11 En Internet existen muchas páginas que recogen cuestiones sobre el léxico de la economía en español. En el anexo 2 se exponen algunos de los diccionarios y glosarios que pueden consultarse en ella. 


\subsubsection{Actividad 2. La ironía como recurso transmisor de una ideología}

Junto a esta primera actividad, también se puede poner en práctica una segunda que profundiza en el concepto de ironía (Ruiz Gurillo y Padilla, 2009) que aparece de forma regular en esta lengua de especialidad. Nos referimos a la titulada ¿Mienten las palabras? (Martínez Egido, 2008b) ${ }^{12}$. Esta actividad debe plantearse y realizarse una vez que el alumno ha estudiado los principios básicos de la creación de términos en español y ha comprobado su uso en diferentes documentos tipificados del español de los negocios, además de haber realizado la primera actividad reseñada para comprender el funcionamiento de todos los recursos, ya que, esta herramienta lingüística requiere de una mayor madurez lingüística, sobre todo si los alumnos son de E/LE.

Esta actividad se estructura de la siguiente forma:

1) Se hace una pequeña introducción por parte del profesor y se presenta la actividad con una plantilla para cada alumno que recoge los siguientes enunciados con algunas palabras subrayadas:

1. A los grandes se les cruzan los cables

2. Faustino exhibe su músculo

3. Maldon, salero inglés

4. Hoteles de primera con "reservas"

5. La altura sí importa

6. Vuelling se estrella por los billetes baratos

7. Inversores de "bolsa".

2) Deben definir cada una de las expresiones subrayadas, independientemente del contexto en el que aparecen, es decir, como unidades léxicas del español general.

3) A continuación se les da un documento con las definiciones que recoge el $D R A E$ en su edición electrónica (www.rae.es) y deben comparar sus propias definiciones con las ofrecidas por el diccionario y anotar el número de la acepción que coincida con las suyas.

4) Puesta en común bajo la dirección del profesor en la que deben quedar claramente expuestas las posibles definiciones de las unidades estudiadas relacionadas con el ámbito de los negocios.

5) Deben crear un contexto de uso de la noticia que pueda corresponderse con cada uno de los siete enunciados.

12 En la publicación de esta actividad puede encontrarse una descripción detallada de su desarrollo, una temporalización de cada uno de sus pasos y todas las plantillas e informaciones necesarias para poder ser llevada al aula. http://marcoele.com/downloads/mientenlaspalabras.pdf 
6) Una vez redactados los siete contextos, se les entregan las entradillas reales de cada uno de los titulares ${ }^{13}$. Ahora tienen que observar mediante la comparación si su contexto se puede asemejar al real proporcionado por la entradilla periodística.

7) Puesta en común bajo la dirección del profesor. Una vez que se han comentado los diferentes aciertos o desvíos redactados por los alumnos, se debe concluir con la explicación de la ligazón real y directa que se establece entre el titular y su entradilla.

8) Cada alumno debe explicar de forma individual los posibles mecanismos de los que se ha servido el periodista económico para redactar su noticia, es decir, debe explicar la relación existente entre la entradilla, que contiene la noticia objetiva, y el titular, que desprende en primer lugar una lectura subjetiva.

9) Una vez observados los siete textos, deberán redactar brevemente el mecanismo que ha operado en cada uno de ellos.

10) Puesta en común bajo la dirección del profesor. A partir de los datos extraídos se explicará en qué consiste la ironía implícita en los enunciados que la contengan y se discriminará la presencia o la ausencia de la ironía.

11) Conclusiones por parte del profesor:

a) Existen expresiones de la lengua estándar que funcionan con normalidad en el lenguaje de los negocios mediante la práctica de la ironía en múltiples ocasiones, la cual produce un significado connotado muy operativo para la finalidad comunicativa que persigue el emisor con su texto.

b) La ironía se produce con la confrontación del significado denotado con el connotado en un acto comunicativo concreto, en ocasiones con marcadores irónicos concretos y, en otros momentos, con la confrontación con el conocimiento del mundo que tenga el receptor. Las palabras aunque parece que mientan, no lo hacen nunca.

c) Para entender la ironía en cada uno de los enunciados propuestos en los que aparece se tiene que contar con el contexto que se ofrece posteriormente en la entradilla. Se produce por tanto un eco catafórico.

\section{Conclusiones}

Delimitados los conceptos de lengua de especialidad, como variantes o registros funcionales de comunicación en un ámbito profesional, y de lengua de especialidad económica, como la realizada en todo el contexto que configura la temática eco-

13 Todas las entradillas se encuentran en el anexo 1 que recoge las 50 noticias que nos están sirviendo para plantear este trabajo. 
nómica, se define el español de los negocios como una variante de la lengua de la economía que permite la comunicación entre no expertos y que, por tanto, entrelaza los aspectos más técnicos con los divulgativos.

Dada la realidad social actual, en necesario que todos podamos ser competentes en el español de los negocios, de ahí que debamos desarrollar dicha competencia por lo que debe ser enseñada en las clases de español de los negocios, tanto para alumnos españoles como para alumnos de E/LE.

El estudio del léxico del español de los negocios y, en concreto, el del español de la economía divulgativo debe abordarse desde una perspectiva funcional, mediante diferentes actividades como las que aquí se han propuesto.

De esta forma, el estudiante del español de los negocios conocerá, además del léxico marcado como terminología ad hoc, tanto el tipo de léxico no técnico pero sí muy utilizado en este ámbito, como los mecanismos lingüísticos que procuran unas intenciones comunicativas, no siempre muy claras, en los mensajes periodísticos de la prensa española actual.

\section{Referencias bibliográficas}

Alcaraz Varo, E. (2000): El inglés profesional y académico. Madrid, Alianza Editorial.

Alcaraz Varo, E., Mateo Martínez, J. y F. Yus Ramos (eds.) (2007): Las lenguas profesionales y académicas, Ariel, Barcelona.

Álvarez Martínez, M. A. (ed.) (1990): Actas del Congreso de la Sociedad Española de Lingüística, $X X$ aniversario. Madrid, Gredos.

Bungarten, T. (1990): "Lengua común y lenguaje especializado. Aspectos de una teoría del lenguaje especializado". En Álvarez Martínez, M. A. (ed.), págs. 880-888.

Cabré, M. T. (1993): La terminología. Teoría, metodología, aplicaciones. Barcelona, Ediciones Antártida

Cabré, M. T. (1999): La terminología. Representación y comunicación. Una teoría de base comunicativa y otros artículos. Barcelona, Institut de Lingüística Aplicada, Universitat Pompeu Fabra.

Calvi, M. V. y L. Chierichetti (eds.) (2006): Tendencias en el discurso de especialidad. Frankfurt, Peter Lang.

Coromina, J. (1980): Diccionario crítico etimológico castellano e hispánico, 5 vols., Madrid, Gredos.

Coseriu, E. (1962): Teoría del lenguaje y Lingüística general. Madrid, Gredos.

Dick, S. (1997): The Theory of Funcional Grammar. Berlín-Nueva York, Mouton de Gruyter.

Dijk, T. A. van (2000): El discurso como estructura y proceso. Barcelona, Gedisa.

Eggins, S. y J. R. Martin (2000): "Géneros y registros del discurso". En Dijk, T. A. van, págs. 230-256.

Felices Lago, A. (2005): "El español con fines específicos y su desarrollo en España durante la última década", IDEAS (FH-Heilbronn), 1, marzo, se realiza una síntesis de esta cuestión http://www.ideas-heilbronn.org/archivo/1/elements/artic/FelicesLago-El-desarollo. pdf (01-06-09). 
Hoffman, L, (1976): Kommunikationsmittel Fachsprache: Eine Einführung. Berlín, Akademie-Verlag.

Hoffman, L. (1998): From Term to Specialized Text. Tübinguen, Gunter Narr Verlag.

Martínez Egido, J. J. (2006): "El español escrito de los negocios: rasgos morfosintácticos", Nueva Frecuencia L, 32, págs. 48-50.

Martínez Egido, J. J. (2007a): Constitución del léxico español. Palabras patrimoniales, cultas y semicultas. Latinismos. Arabismos. Helenismos. Madrid, Liceus, Servicios de Gestión y Comunicación S.L. http://www.liceus.com/bonos/compra1.asp?idproducto=1073 (05-05-09)

Martínez Egido, J. J. (2007b): Galicismos. Italianismos. Lusismos. Anglicismos. Voces de otra procedencia. Madrid, Liceus, Servicios de Gestión y Comunicación S.L. http:// www.liceus.com/bonos/compra1.asp?idproducto=1118 (05-05-09)

Martínez Egido, J. J. (2008a): El español de los negocios. Alicante, RUA, http://ocw.ua.es/ Humanidades/espanol-negocios/Course_listing

Martínez Egido, J. J. (2008b): ¿Mienten las palabras?, MarcoEle, 6, http://marcoele.com/ downloads/mientenlaspalabras.pdf

Martínez Egido, J. J. (en prensa): “Constitución del léxico utilizado en la prensa económica actual", Español Actual.

Mateo Martínez, J. (2007): “El lenguaje de las ciencias económicas”. En Alcaraz Varo, E., Mateo Martínez, J. y F. Yus Ramos (eds.), págs. 191-203.

Moreno, F. (1998): Principios de sociolingüística y sociología del lenguaje. Barcelona, Ariel.

RAE, DRAE, en línea (www.rae.es)

Rondeau, G. (1983): Introduction à la Terminologie. Quebec, Gaëtan Morin.

Ruiz Gurillo, L. (2006): Hechos pragmáticos del español. Alicante, Universidad de Alicante.

Ruiz Gurillo, L. y X. Padilla García (eds.) (2009): Dime cómo ironizas y te diré quién eres. Una aproximación pragmática a la ironía. Frankfurt, Peter Lang.

Sager, J. C. (ed.) (1993): Curso práctico sobre el procesamiento de la terminología. Madrid, Fundación Germán Sánchez Ruipérez.

Saussure, F. de (194524): Curso de lingüística general. Buenos Aires, Losada.

Tamames, R, y S. Gallego $\left(2000^{11}\right)$ : Diccionario de Economía. Alianza Editorial, Madrid. Verschueren, J. (2002): Para entender la pragmática. Madrid, Gredos. 


\section{ANEXO 1: TITULARES Y ENTRADILLAS DE NOTICIAS DE PRENSA DEL PERIÓDICO EL PAÍS (MAYO-JUNIO 2007)}

1) Telefónica esprinta en Europa. La multinacional española se convierte en referente de las telecomunicaciones europeas batiendo a sus rivales por rentabilidad, clientes y capitalización bursátil (pág. 1; 20-05-07).

2) Telefónica marca el paso en Europa. La operadora española bate a sus rivales y se convierte en motor de las telecomunicaciones europeas (pág. 5, 20-05-07).

3) A los grandes se les cruzan los cables. Deutsche Telekom, France Télécom y Telecom Italia pasan por malos momentos (pág. 6, 20-05-07).

4) Acerinox tiene muy alto el listón. El precio del níquel dispara sus beneficios, pero empeora sus expectativas de resultados futuros (pág. 9, 20-05-07).

5) Faustino exhibe su músculo. El grupo bodeguero riojano apuesta por la diversificación tras invertir 25 millones en la Ribera del Duero. Puesta de largo de la mano de Norman Foster (pág. 10, 20-5-07).

6) Habla pero seguro. Mossec ofrece soluciones para proteger la información en los móviles (pág. 11, 20-5-07).

7) Eroski, una cesta familiar. La facturación por servicios supone ya más del $15 \%$ de todas las ventas del grupo (pág. 12, 20-05-07).

8) Zumos para una guerra. Don Simón denuncia otra vez a Pascual por publicidad engañosa. (pág. 13, 20-05-07).

9) Colonial se viste de largo. Tras la fusión con Inmocaral gana 205 millones en el tránsito (pág. 21, 20-05-07).

10) Googles, la más deseada. El buscador se convierte en la firma preferida de los estudiantes de MBA de EEUU para trabajar (pág. 33, 20-05-07).

11) El error de las broncas. Los jefes que riñen se perjudican a sí mismos (pág. 1, 17-06-07).

12) La unión hace la fuerza. Las buils ups creadas desde la nada a partir de la suma de firmas muy pequeñas se ponen de moda en España. (pág. 5, 17-06-07)

13) Don Simón gana la guerra del frío. Pascual no podrá anunciar como refrigerados los zumos fabricados a temperatura ambiente (pág. 9, 17-06-07).

14) Realia patina en su semana de estreno (pág. 10, 17-06-07).

15) Vestas saca pecho con el viento. La industria eólica no es capaz de atender el tirón de la demanda mundial de molinos (pág. 15, 17-06-07).

16) Un vendaval indio irrumpe en el mercado eólico (pág. 15, 17-06-07).

17) Locomotora en marcha. La economía alemana vuelve a ser un pilar del crecimiento de la UE (pág. 19-17-06-07).

18) Goteo de salidas a Bolsa. Al menos diez empresas planean empezar a cotizar este año, apoyadas en los altos precios del mercado (pág. 22, 17-06-07).

19) Un asesor para los pequeños. Norbolsa Asesoramiento y Adquisiciones coquetea con las pymes (pág. 23, 17-06-07). 
20) Iberia la novia más solicitada. La mayor compañía aérea española se deja querer y exhibe su buena salud económica (pág. 1, 15-07-07).

21) Aires revueltos en Europa. Las líneas aéreas europeas preparan su consolidación en tres grandes grupos (pág. 6, 15-07-07).

22) Juan Ramón Quintás, presidente de la CECA: “Ahora el Banco de España dejar correr más a las cajas”. Miguel Ángel Fernández Ordónez tiene una actitud menos paternalista, según las cajas de ahorros. (pág. 8, 15-07-07).

23) Mucha tela por cortar. La multinacional textil Puig Codina decide crecer apostando por el mercado latinoamericano (pág. 10, 15-07-07).

24) Dogi da el tijeretazo para salir del túnel. El grupo textil se encuentra en pérdidas desde 2001 pese a su fuerte implantación en Asia (pág. 11, 15-07-07).

25) Maldon, salero inglés. El grupo familiar británico triunfa en España de la mano de los grandes 'chefs' (pág. 13, 15-07-07).

26) Los zumos se pelean en la publicidad. Don Simón y Pascual se intercambian denuncias por la veracidad de los anuncios (pág. 14, 15-07-07).

27) Un rally con pocos accidentados. La industria española está asumiendo sin grandes problemas el fuerte y rápido crecimiento de las materias primas (pág. 16, 15-07-07).

28) Pensiones que brillan con la bolsa. Los planes privados que pueden servir de modelo inversor frente al fondo público de reserva acumulan fuertes revalorizaciones (pág. 21, 15-07-07).

29) Banco Popular sale de compras. Adquiere TotalBank, un pequeño banco en Estados Unidos (pág. 22, 15-07-07).

30) Días de vino y rosas por el mercado del arte (pág. 1, 22-07-07).

31) Hoteles con mucha vista. A pesar de la buena salud de las cadenas españolas, peligra su futuro si no ganan pronto tamaño con compras y fusiones (pág. 5, 22-07-07).

32) Hoteles de primera con "reservas". A pesar de la buena salud de las cadenas españolas, peligra su futuro si no ganan pronto tamaño con compras y fusiones (pág. 5, 22-07-07).

33) Gesfor da la talla en Latinoamérica. El grupo tecnológico vasco confía su futuro a un área que le aporta ya el 30\% de su facturación (pág. 11, 22-07-07).

34) Mediolanum pone las pilas a Fibanc. Gestiona ya en España 2.739 millones y prevé acabar 2007 con una red propia de 600 agentes (pág. 14, 22-07-07).

35) El tomo ha muerto, viva la red. El Derecho (editorial jurídica), que ha acabado su transición del papel y el CD a internet, busca nuevos servicios (pág. 15, 22-07-07).

36) Ciberagricultores. Han hecho de una web su mostrador y vende 50.000 kilos de granadas (pág. 17, 22-07-07).

37) Inversiones con firma. Una gran liquidez, la especulación y la incorporación de China al coleccionismo, catapulta el mercado del arte mundial (pág. 23, 22-0707). 
38) Parqués en estado de nervios. Nueva semana de infarto en la Bolsas mundiales, mientras que el Ibex pierde sus ganancias anuales (pág. 1, 19-08-07).

39) Fiebre hipotecaria. Crece la morosidad en el mercado español (pág. 1, 19-0807).

40) Guerra de comisiones, más ruido que nueces. La banca mejora su margen de intermediación por el alza de tipos, pero se resiste a reducir sus ingresos por este concepto (pág. 5, 19-08-07).

41) Tetra Pak reta al vidrio. El grupo apuesta por un envase barato que conserve las cualidades del aceite de oliva (pág. 10, 19-08-07).

42) La cucaracha hipotecaria. Crece la morosidad de los créditos para vivienda, que se ha encarecido más de 200 euros en los dos últimos años (pág. 12, 1908-07).

43) De Madrid al cielo desde la Castellana. Cuatro torres suplirán la falta de oficinas de lujo (pág. 1, 12-08-07).

44) La altura sí importa. Las cuatro torres de la Castellana reforzarán la imagen de Madrid como centro internacional de negocios (pág. 5, 12-08-07).

45) Con el pez detrás de la oreja. Buenos Aires indemnizará a las pesquerías asaltadas por los marineros de la Patagonia (pág. 6, 12-08-07).

46) Vueling se estrella por los billetes baratos. La aerolínea española, que ayer presentó pérdidas por 26 millones y cedió casi un tercio de su valor en Bolsa, dice que a 40 euros de precio medio por pasaje es difícil ser rentable (pág. 57, 04-08-07).

47) Las compañías cotizan satisfacción. Mejoran sus ventas, ganancias y expectativas hasta el 30 de junio, según el Barómetro de empresas (pág. 1, 29-07-07).

48) Las ventas catapultan las ganancias. Ocho de cada diez empresas encuestadas afirman haber aumentado su beneficio bruto en el segundo trimestre (pág. 6, 29-07-07).

49) Una mujer de altos vuelos. Mercè Martí convierte en empresa su afición y factura 450.000 euros (pág. 11, 29-07-07).

50) Avanzit, a la búsqueda del tiempo perdido. Ultima la salida a bolsa de Vértice $360^{\circ}$ y quiere recuperar en tres años las cifras de 2000 (pág. 12, 29-07-07). 


\section{ANEXO 2: RECURSOS LÉXICOS EN LA RED. (08/02/2009)}

- http://www.finanzas.com/servicios/diccionario/resultados?gclid=Cleq6umtzZgC FQ6wQwod9GaT0w Diccionario de Economía que admite la búsqueda de un término concreto.

- http://www.eumed.net/cursecon/dic/index.htm:

- Catálogo de Términos Contables

- Catálogo de términos para Administradores Concursales

- Diccionario básico tributario-contable

- Diccionario de Economía y Finanzas de Carlos Sabino

- Diccionario de Economía Política de Borísov, Zhamin y Makárova

- Diccionario Económico de Nuestro Tiempo recopilado por Manuel Serra Moret

- Glosario del asegurado

- Glosario del inversionista

- Glosario básico de microeconomía

- Glosario de conceptos políticos usuales de Eduardo Jorge Arnoletto

- Glosario de Mercados Financieros

- Glosario de términos de logística (AAGO)

- Glosario de términos en plásticos (AAGO)

- Otros conceptos

- Términos Comerciales Internacionales INCOTERMS 2000

- Vocabulario de Economía Política de José Manuel Piernas y Hurtado

- http://www.gratisweb.com/economiafacil/diccionario.htm No permite la consulta por entrada sino por la letra de inicio.

- http://www.economia48.com Diccionario con más de 10.000 entradas.

- http://es.biz.yahoo.com/gloss/main/index.html Diccionario que se actualiza constantemente. Explica de forma técnica unidades léxicas de uso común.

- http://www.econlink.com.ar/dic.shtml Diccionario enciclopédico, cuyos artículos contienen una extensa microestructura.

- http://www.ecobachillerato.com/diccionario.htm Diccionario destinado a los alumnos de Bachillerato para la asignatura de Economía.

- http://economy.blogs.ie.edu/archives/2008/02/diccionario_ver.php Diccionario en PDF.

- http://www.e-torredebabel.com/Economia/diccionario-economia/vocabularioeconomia.htm Diccionario de 1919 de José Manuel Piernas Hurtado.

- http://www.glosarium.com/list/12/index.xhtml Glosario de términos económicos mexicano. 
- http://www.n-economia.com/glosario/glosario.asp?l=0\&c=A Ofrece la traducción del término al inglés.

- http://www.pdf-search-engine.com/diccionario-de-economia-pdf.html Recursos diferentes en la Red.

- http://portal.lacaixa.es/docs/diccionario/A_es.html Diccionario de términos económicos y financieros de La Caixa.

- http://obneo.iula.upf.edu/spes Diccionario de neologismos de la Universidad Pompeu i Fabra.

- http://cvc.cervantes.es/obref/banco_neologismos/listado_neologismos.asp Banco de Neologismos

- http://www.yoescribo.com/publica/libreria/neologismos.aspx?cod=305 Diccionario de neologismos que se va construyendo con las aportaciones de los lectores. 
